Revista de Educação e Pesquisa em Contabilidade Journal of Education and Research in Accounting Revista de Educación e Investigatión en Contabilidad
REPeC, Brasília, v. 6, n. 4, art. 1, p. 351-366, out./dez. 2012 Disponível online em www.repec.org.br

ISSN 1981-8610

\title{
Redução ao Valor Recuperável de Ativos: um Estudo nas Empresas do Setor Petrolífero Mundial
}

\author{
João Carlos de Aguiar Domingues \\ Mestre em Controladoria e Contabilidade (FEA-RP/USP) e Doutorando em Administração de Organizações (FEA-RP/USP). \\ Professor Substituto da Universidade de São Paulo (FEA-RP/USP). \\ Av. Bandeirantes, 3900, Bairro Monte Alegre, CEP: 14040-905, Ribeirão Preto (SP) \\ E-mail: joaocarlosdomingues@uol.com.br
}

\section{Carlos Roberto Godoy}

Doutor em Controladoria e Contabilidade (FEA/USP).

Professor Doutor da Universidade de São Paulo (FEA-RP/USP).

Av. Bandeirantes, 3900, Bairro Monte Alegre, CEP: 14040-905, Ribeirão Preto (SP)

E-mail: crgodoy@usp.br

\section{Resumo}

A atividade de exploração e produção de óleo e gás (E\&P) caracteriza-se por ser tipicamente de capital intensivo, envolver altos riscos e longos prazos de maturação dos investimentos. Essas características refletem em valores elevados dos ativos empregados e dificuldades na recuperação desses valores capitalizados. Assim, o teste para verificar a possibilidade de recuperação dos valores dos ativos - impairment - tem importância acentuada para este setor. Nesse contexto, o presente trabalho teve por objetivo realizar uma análise para se identificar como as variações no preço do petróleo e nas reservas provadas se relacionam com as despesas de impairment atribuídas às atividades de $\mathrm{E} \& \mathrm{P}$ de petróleo. Constatou-se que existe uma relação inversa entre as despesas de impairment atribuídas às atividades de E\&P e o volume de descobertas e o saldo líquido de compra e venda de reservas. Entretanto, o estudo não confirmou que o preço e o volume de reserva tenham relação inversa com a despesa de $\mathrm{im}$ pairment. Também não foi confirmada a relação direta entre produção e perda por impairment.

Palavras-chaves: Impairment; IAS 36; SFAS 144; Petróleo e Gás; Contabilidade para o setor petrolífero.

Editado em Português, Inglês e Espanhol. Versão original em Português.

Recebido em 12/07/2011. Pedido de Revisão em 15/12/2011. Resubmetido em 17/01/2012. Aceito em 20/03/2012 por Valcemiro Nossa (Editor). Publicado em 30/11/2012. Organização responsável pelo periódico: CFC/FBC/ABRACICON.

Copyright (C) 2012 REPEC. Todos os direitos, até mesmo de tradução, são reservados. É permitido citar parte de artigos sem autorização prévia, desde que seja identificada a fonte. 


\section{INTRODUÇÃO}

Cada setor industrial apresenta suas características operacionais nos negócios e nas práticas contábeis, mas é raro o setor em que se encontram tantas particularidades nas operações industriais, na gestão e na contabilidade quanto o setor petrolífero (IJIRI, 1979, apud WOLK, FRANCIS e TEARNEY, 1984).

A contabilidade para o setor petrolífero e, consequentemente, sua evidenciação, são caracterizadas por vários problemas teóricos e técnicos, que historicamente, resumem-se na impossibilidade dos analistas e investidores usarem os dados das demonstrações financeiras para avaliar o patrimônio das empresas. O que vemos com isso é a exigência de informações financeiras e operacionais adicionais sobre a atividade de explorar e produzir petróleo (por exemplo, SFAS 69 e Regulation S-X 4-10).

Os problemas enfrentados pela contabilidade em empresas do setor de óleo e gás são consequências das características ímpares desta indústria: 1) alto risco de encontrar poços secos; 2) distância temporal entre a descoberta de reservas e a realização em lucro ou em caixa; 3) dissociação entre os gastos (investimentos), receitas e valor das reservas (retornos); e 4) a importância estratégica que a commodity ganhou nos mercados internacionais e, principalmente, como fonte energética para os países (CLÔ, 2000).

Essas características podem ser observadas em quaisquer fases da indústria, mas torna-se evidente quando se observa o seu principal segmento (atividade): a exploração e produção (E\&P) de petróleo e gás (GALLUN, STEVENSON e NICHOLS, 1993). É essa atividade que registra os maiores valores de ativos e os maiores ganhos (lucros) em uma petrolífera.

De acordo com Godoy (2004), essas características singulares fazem com que a atividade de E\&P de petróleo e gás apresente dificuldades na recuperação dos valores investidos - capitalizados. Notadamente, os testes para se verificar a recuperabilidade dos valores dos ativos (investidos) ganham importância acentuada para o setor e, principalmente, para a atividade de E\&P (GALLUN; STEVENSON; NICHOLS, 1993; GODOY, 2004; BROCK; CARNES; JUSTICE, 2007).

No Brasil, com a aprovação da Lei no 11.638 , em 28 de dezembro de 2007, resultado do Projeto de Lei $n^{0} 3.741 / 2000$, ficou obrigatório o teste de recuperação dos valores registrados nos ativos imobilizados das sociedades anônimas e empresas de grande porte.

Na essência, o teste de impairment busca verificar a perda de recuperabilidade dos ativos, ou seja, identificar ativos cujas expectativas de fluxos de caixa foram diminuídas substancialmente em virtude de situações adversas. Uma vez identificados, esses ativos não podem permanecer evidenciados no balanço com seus valores originais, já que esses valores não mais demonstram a capacidade de geração de benefícios econômicos futuros (STICKNEY; WEIL, 2001).

Atualmente, as principais normas que orientam a aplicação do teste de impairment são: a) SFAS 144 - Accounting for the Impairment or Disposal of Long-Lived Assets, do Financial Accounting Standards Board (FASB); b) IAS 36 - Impairment of Assets, do International Accounting Standards Board (IASB); e c) CPC 01 - Redução ao Valor Recuperável de Ativos, do Comitê de Pronunciamentos Contábeis (CPC).

Para as empresas do setor petrolífero a diversidade de normas aumenta, pois além de seguirem as normas de impairment aplicadas às empresas em geral, devem seguir também aquelas específicas do setor.

De acordo com as normas brasileiras, além das orientações contidas no CPC 01, as empresas petrolíferas também deverão seguir o CPC 34 - Exploração e Avaliação de Recursos Minerais. Para empresas que seguem as normas emitidas pelo IASB, além da IAS 36, as empresas deverão seguir a IFRS 6 - Exploration for and Evaluation of Mineral Resources.

Já para aquelas atreladas às normas norte americanas, as regras variam de acordo com a característica do ativo testado e com o método de capitalização dos gastos adotado pela empresa. Para os ativos associados às propriedades não provadas de petróleo e gás, a regra está disposta na SFAS 19 - Financial Accounting and Reporting by Oil and Gas Producing Companies. Para os ativos associados às propriedades provadas de petróleo e gás, a regra dependerá do método de capitalização dos gastos adotado: empresas que utilizam o método conhecido como Capitalização Total (Full Cost $-F C)$ devem utilizar a 
Regulation S-X Rule 4-10 - Financial Accounting and Reporting for Oil and Gas Producing Activities Pursuant to the Federal Securities Laws and the Energy Policy and Conservation da Securities and Exchange Commission (SEC); empresas que adotam o método de Capitalização pelos Esforços Bem Sucedidos (Sucessful Efforts - SE), a regra a ser seguida é a SFAS 144, do FASB.

Independente da norma seguida, as situações adversas que causam impairment são comuns às empresas petrolíferas, pois estão diretamente relacionadas com as características inerentes dos ativos usados para explorar e produzir petróleo e gás. São elas: a) alterações nos preço das commodities (petróleo e gás), e b) mudança nas estimativas das reservas de petróleo e gás, que por sua vez são afetadas por revisões nas estimativas, melhorias de recuperação de reservas, descobertas, compras e vendas de reservas e produção. Essas alterações podem ser consideradas variáveis que afetam o cálculo do valor recuperável do ativo e que, consequentemente, afetam a perda por impairment (ALCIATORE; EASTON; SPEAR, 2000; BROCK, CARNES; JUSTICE, 2007).

Diante disso, o presente trabalho levanta a seguinte questão: Qual a relação do preço do petróleo e do volume de reservas provadas e suas alterações com a perda do valor de recuperação (impairment) atribuída aos ativos de E\&P de petróleo nas empresas petrolíferas, e quais as diferenças entre as principais normas sobre impairment (SFAS 144, IAS 36 e CPC 01)?

Com isso, este trabalho objetiva realizar uma análise para se identificar como as variações no preço do petróleo e nas reservas provadas se relacionam com as despesas de impairment atribuídas as atividades de E\&P de petróleo e gás das empresas do setor petrolífero.

Como objetivo complementar o estudo pretende realizar um levantamento dos principais pronunciamentos do FASB (SFAS 144), IASB (IAS 36) e CPC (CPC 01) sobre desvalorização de ativos, evidenciando suas principais divergências.

Para responder a questão da pesquisa e, assim, atingir os objetivos propostos este trabalho está estruturado da seguinte forma: o item 2 aborda os aspectos conceituais relacionados à perda do valor de recuperação de um ativo, a SFAS 144, a IAS 36, o CPC 01 e apresenta uma análise comparativa das normas. No item 3 é apresentada a metodologia da pesquisa empírica; no 4 são levantadas proposições quanto às evidencias empíricas; no item 5 os resultados e; finalmente no item 6 , as considerações finais.

\section{REFERÊNCIAL TEÓRICO}

\subsection{O ativo e a Perda do Seu Valor de Recuperação}

Levando em consideração o conceito de valor econômico, as empresas deveriam, independente de qualquer aspecto legal, avaliar, periodicamente, o grau de recuperabilidade de seus ativos. (REISTEM; LANDER, 2004; MARTINS, 2008).

O teste de recuperabilidade é um procedimento que, teoricamente, deve ser praticado em todos os ativos do balanço. Sua metodologia já era praticada de forma despercebida para alguns ativos, como estoques, quando se mensurava seu valor pelo custo ou mercado, dos dois o menor; e para as contas a receber, quando se reconhecia uma provisão para ajuste dos créditos a seu valor de realização ou a tradicional provisão para créditos de liquidação duvidosa, antiga provisão para devedores duvidosos (MARTINS; SANTOS, 2008; ERNEST \& YOUNG, 2009).

Do ponto de vista da avaliação do ativo, o impairment objetiva adequar o valor registrado pela contabilidade à capacidade de geração de benefícios futuros do ativo, ou seja, pratica-se a avaliação do ativo por meio do fair value (RIELD, 2004).

Talvez, o aspecto negativo seja o fato de a prática do impairment implicar em desafios significativos na sua divulgação, pois atribui às demonstrações contábeis certo grau de subjetividade, uma vez que requer julgamentos e estimativas (RIELD, 2004).

$\mathrm{Na}$ tentativa de aproximar os relatórios gerenciais que analisam a viabilidade econômica dos investimentos às informações divulgadas ao mercado, os órgãos normatizadores de contabilidade emanaram algumas normas contábeis sobre o teste de recuperação de ativos. 


\subsection{SFAS 144: Accounting for the Impairment or Disposal of Long-lived Assets}

De acordo com a SFAS 144, impairment é uma condição que existe quando a quantia registrada de um ativo ou grupo de ativos for superior ao seu valor justo. O valor registrado de um ativo, ou grupo de ativos, é considerado não recuperável se exceder a soma dos fluxos de caixa líquidos não descontados esperados, decorrentes do uso e eventual venda do ativo.

Nesse sentido, uma perda do valor recuperável é determinada pela comparação do valor contábil do ativo (ou grupo de ativos) com os fluxos de caixa líquidos futuros não descontados projetados para esse ativo. Em outras palavras, quando o primeiro for maior que o segundo dever ser reconhecida uma perda por impairment.

De acordo com a SFAS 144, os ativos ou grupos de ativos devem ser testados durante sua vida útil quando eventos ou mudanças nas circunstâncias indicarem que a sua quantia escriturada pode não ser recuperável. A norma elenca as seguintes situações que podem indicar perda do valor de recuperação: (i) uma diminuição significativa no preço de mercado do ativo (ou grupo de ativos); (ii) uma modificação adversa significativa na extensão ou no modo pelo qual o ativo (ou grupo de ativos) é utilizado ou, uma modificação em suas condições físicas; (iii) uma modificação adversa significativa em fatores legais, regulamentações de órgãos de controle ou no ambiente empresarial que poderia afetar o valor do ativo; (iv) uma acumulação de custos significativamente superiores ao montante inicialmente previsto para a aquisição ou a construção do ativo (ou grupo de ativos); (v) perdas atuais operacionais ou no fluxo de caixa, combinadas com um histórico ou projeções de perdas com o uso de um ativo ou grupo de ativos e (vi) expectativa maior que 50\% de que um ativo (ou grupo de ativos) será vendido ou baixado antes de sua vida útil estimada.

Estas orientações ganham complexidade quando é levada em consideração a existência de um grupo de ativos (REINSTEIN; LANDER, 2004). A SFAS 144 define grupo de ativos como a menor unidade de agregação de bens que são capazes de produzir entradas e saídas de caixa independentes em relação a outros ativos (ou grupos de ativos) da empresa. Podem agregar somente alguns ativos, não constituindo uma "unidade de relatório", ou podem até considerar a empresa como um todo.

Portanto, no momento de realizar o reconhecimento e a mensuração da perda por impairment, as empresas devem agrupar os ativos com outros ativos e obrigações até o menor nível para o qual forem identificados fluxos de caixa amplamente independentes de fluxos de caixa de outros ativos e passivos, formando então um grupo de ativos (REINSTEIN; LANDER, 2004).

Nesta situação, a SFAS 144 define que o tempo de vida útil remanescente do grupo de ativos será baseado no tempo de vida útil remanescente do ativo primário do grupo. Ativo primário é aquele ativo que, sem ele, o grupo de ativos não conseguirá produzir fluxos de caixa futuros independentes, ou que seu valor contábil individual possua uma grande representatividade em relação ao total do grupo testado.

Por fim, o valor da perda por impairment é definido pela diferença entre o valor contábil e a soma dos fluxos de caixa descontados. Esse valor é lançado para resultado no período relativo ao teste. Os efeitos contábeis desta perda produzem alterações nas contas originais dos respectivos ativos, evidenciando a adoção do novo valor contábil ajustado pela perda por impairment como a base para as futuras depreciações/amortizações, bem como para futuros testes de recuperação do valor contábil do ativo (REINSTEIN; LANDER, 2004). A SFAS 144 define ainda que uma vez reconhecida a perda por impairment, fica proibida sua reversão.

Com relação à divulgação, devem constar em notas às demonstrações financeiras que incluem o período em que a perda por impairment é reconhecida: a) descrição do ativo (ou grupo de ativos) que sofreu perda por impairment, assim como os fatos e as circunstâncias que justificam o prejuízo; b) o valor da perda por impairment e a conta na demonstração de resultado que inclui a perda, se esta não tiver sido apresentada em outro relatório; c) o método ou métodos utilizados para determinar valor justo, e d) caso o ativo (ou grupo de ativos) que sofreu a perda seja componente de um segmento operacional, a SFAS 144 indica que deverão ser respeitadas as orientações constantes na SFAS 131 - Evidenciação de Informações por Segmentos (Disclosures about segments of an enterprise and related information). 


\section{repec}

\subsection{IAS 36 - Impairment of Assets}

A IAS 36 objetiva definir procedimentos visando assegurar que os ativos não estejam registrados contabilmente por um valor superior àquele passível de ser recuperado por uso ou por venda. Caso existam evidências de que ativos estejam registrados por valores não recuperáveis no futuro, a entidade deverá realizar o teste para verificar a possível perda e, caso identificada, reconhecer a desvalorização por meio da constituição de provisão para perdas de recuperabilidade de ativos

O valor recuperável de um ativo ou de uma unidade geradora de caixa é o maior valor entre o valor líquido de venda e o seu valor em uso; o valor em uso é o valor presente de fluxos de caixa futuros estimados.

As orientações da IAS 36 abrangem a contabilização de impairment para quase todos os tipos de ativos, incluindo ativos fixos, ativos intangíveis e goodwill. No entanto, não se aplica a alguns ativos para os quais existem normas específicas que orientam o seu reconhecimento e a sua mensuração.

A entidade deve avaliar ao final de cada período, se existe qualquer indicação de que o ativo tenha perdido substância econômica. Se qualquer indicação existir, deve-se estimar a quantia recuperável do ativo. Como indicadores de desvalorização de seus ativos a norma apresenta exaustiva lista de fontes de informações, classificadas em fontes externas e fontes internas.

As principais informações externas que devem ser observadas são: a) se o valor de mercado de um ativo diminuiu mais do que o esperado, em função do tempo e de sua utilização; b) se ocorreram mudanças significativas no ambiente tecnológico, de mercado, econômico ou legal, de forma a afetar os ativos da entidade; c) se os juros aumentaram a ponto de afetar a taxa de desconto utilizada no cálculo do valor do ativo em uso (fluxo de caixa); e d) se o valor contábil líquido dos ativos for maior do que seu valor de mercado capitalizado.

Já as informações internas são: a) evidências que comprovem que o ativo está obsoleto ou danificado; b) mudanças significativas quanto ao modo de uso do ativo, incluindo a sua descontinuidade; e c) a indicação de queda superior ao esperado do desempenho econômico de um ativo, evidenciado em relatório interno.

Independente desses indicativos, a norma prescreve que a entidade deve testar anualmente a perda de substância econômica para ativos intangíveis com vida útil indefinida e para o goodwill adquirido em uma combinação de negócios.

Em condições gerais, a norma orienta que o valor recuperável deve ser calculado para um ativo individual. No entanto, se não for possível estimar o valor recuperável de um ativo individualizado, pelo fato de os fluxos de caixa gerados por ele serem dependentes dos fluxos gerados por outros ativos, deve ser determinado o valor recuperável para a unidade geradora de caixa (UGC).

A IAS 36 define UGC como o menor grupo identificável de ativos que gera entradas de caixa, que são em grande parte independentes das entradas de caixa de outros ativos ou de grupos de ativos.

Para as empresas do segmento de óleo e gás e, portanto, para os ativos de E\&P, a definição de unidade geradora de caixa é regulada pela IFRS 6-Exploration for and Evaluation of Mineral Resources. Nesta norma, cada unidade geradora de caixa ou grupo de unidades a que um ativo de E\&P seja imputado não deve ser maior do que um segmento de negócio, determinado de acordo com a IFRS 8 - Operating Segments.

Mensurado o valor recuperável de um ativo (ou da UGC), se este for menor do que seu valor contábil, este deve ser reduzido ao seu valor recuperável. Essa redução representa uma perda por desvalorização do ativo e, portanto há impairment. A perda por desvalorização do ativo deve ser reconhecida imediatamente no resultado do período, exceto para aqueles ativos que foram objeto de reavaliação, que terão suas perdas registradas em reservas de reavaliação no patrimônio líquido.

Para se verificar a existência de possível perda de valor nos ativos é necessário apurar o valor líquido de venda deste ativo e ou seu valor em uso. No entanto, se qualquer um deles exceder o valor contábil do ativo, isso já caracteriza a não existência de perda, não sendo necessário que ambos sejam apurados, uma vez que os benefícios advindos da utilização ou da venda do ativo são superiores aos registrados pela entidade. 
No caso de identificação de uma UGC, o valor da perda deve ser alocado, primeiramente, para reduzir a quantia registrada de qualquer goodwill atribuído a ela, para depois ser alocada aos outros ativos constituintes da UGC em uma base pro rata, com base nas quantias registradas de cada ativo.

Outro ponto importante a ser citado é a possibilidade de reversão de uma perda por desvalorização. A entidade deve avaliar em cada data de relatório se há alguma indicação de que uma perda por desvalorização, reconhecida em períodos anteriores para um ativo, possa não existir mais ou ter diminuído. Se existir alguma indicação, a entidade deve estimar um novo valor recuperável desse ativo.

No caso da reversão, a norma também elenca fatos que podem ocorrer e serem indicativos de uma necessidade de reversão. Também os chama de "fontes de informações" e divide-os em fontes externas e internas à entidade.

Como fonte de informação externa à entidade cita-se: a) se o valor de mercado do ativo aumentou significativamente durante o período, b) se ocorreram ou irão ocorrer alterações significativas no ambiente econômico, jurídico e tecnológico em que a empresa opera de forma que tragam efeitos favoráveis a ela, e c) se as taxas de juros do mercado diminuírem significativamente durante o período, ao ponto de serem capazes alterar a taxa de desconto usada no cálculo do valor em uso do ativo.

Como fontes internas cita-se: a) se houveram alterações significativas na forma como o ativo é utilizado e essa mudança gerou efeitos favoráveis a entidade, e b) se existirem relatórios internos que indiquem melhora no desempenho econômico do bem.

Esse aumento no valor contábil de um ativo, atribuível à reversão de perda por desvalorização, não deve exceder o valor contábil que teria sido determinado, líquido de depreciação, amortização ou exaustão, caso nenhuma desvalorização tivesse sido reconhecida em anos anteriores. Qualquer aumento no valor contábil de um ativo, acima do seu valor contábil, é considerado uma reavaliação. A reversão de perdas por imparment deve ser reconhecida no resultado imediatamente, a não ser que o ativo esteja escriturado por valor reavaliado, que neste caso será registrado em reservas de reavaliação no patrimônio líquido.

Com base nas operações realizadas relacionadas à perda de impairment, as principais informações que a entidade deve divulgar, para cada classe de ativos, são: a) o valor das perdas e das reversões, reconhecidas no resultado do período, e a linha na demonstração em que elas foram incluídas; b) os acontecimentos e circunstâncias que levaram ao reconhecimento ou reversão da perda; c) uma descrição da unidade geradora de caixa (se for o caso) e d) a metodologia de avaliação utilizada para a se determinar o valor recuperável do ativo ou de uma UGC: valor líquido de venda ou valor em uso.

\subsection{CPC 01: Redução ao Valor Recuperável de Ativos}

De forma geral, a norma contábil internacional e a brasileira são similares, pois embora não sejam textualmente iguais, apresentam as mesmas orientações. É atendido o objetivo de convergência.

A principal diferença diz respeito à divulgação. A norma contábil brasileira não prevê divulgações específicas acerca de diferentes segmentos de negócio de uma entidade. A norma contábil internacional, por meio da IFRS 8 - Segmentos Operacionais (Operating Segments), define uma série de divulgações requeridas para entidades com mais de um segmento de negócios e segmentos geográficos.

Vale ressaltar que a norma menciona conceitos não habituais para a contabilidade brasileira: fair value; contabilização de ativos intangíveis e segmentos operacionais. Portanto, obstáculos para a sua implementação e impactos significativos nas demonstrações financeiras das empresas brasileiras deverão ocorrer.

\subsection{Análise Comparativa das Principais Normas sobre Impairment}

A primeira grande diferença entre as normas é a abrangência dos ativos alvos de perda. As normas internacional e brasileira são extensivas a ativos intangíveis e ao goodwill, sendo que, para esse último item, o Fasb o trata em uma norma específica (SFAS 142). No entanto, para o presente trabalho, as normas são convergentes quanto à sua aplicabilidade aos ativos de E\&P de empresas petrolíferas integradas que seguem o método da capitalização pelos esforços bem-sucedidos. 
Pela IAS 36 e pelo CPC 01, a determinação e a apuração do valor da perda por impairment, utilizando o valor em uso, se dá pelo cálculo do fluxo de caixa futuro descontado. Já pela SFAS 144, a perda é determinada pelo excesso do fluxo de caixa futuro não descontado sobre o valor registrado, mas a apuração de seu valor é feita pela confrontação do fluxo de caixa futuro descontado com o valor registrado. Isso denota o maior conservadorismo da norma norte-americana sobre as normas do Iasb e do CPC.

Segundo o SFAS 144, a perda por impairment é de natureza permanente, portanto não é permitida sua reversão em exercícios posteriores. Já o Iasb e o CPC permitem a reversão da perda por impairment, caso ocorra mudança nas premissas que geraram tal perda, neste caso o valor de recuperação deve recompor o ativo até o limite de seu valor original. Essa reversão não se confunde com o instrumento da reavaliação de bens, atualmente proibida no Brasil.

Diante de tal análise, constata-se que, apesar de apresentarem consideráveis semelhanças, as diferenças observadas entre as normas comprometem a qualidade da informação contábil e distorce o real objetivo do instrumento - garantir que os registros contábeis retratem o valor dos benefícios econômicos futuros gerados pelos ativos à entidade (AMPOFO; SELLANI, 2005). (Quadro 1)

\begin{tabular}{|c|c|c|c|}
\hline \multicolumn{4}{|c|}{$\begin{array}{l}\text { Diferenças entre a Normatização Contábil para } \\
\text { O teste de recuperabilidade dos valores dos ativos }\end{array}$} \\
\hline $\begin{array}{c}\text { Órgão } \\
\text { Normatizador }\end{array}$ & FASB & IASB & СРC \\
\hline Tópicos & SFAS 144 (agosto de 2001) & IAS 36 (abril de 1998) & CPC 01 (setembro de 2007) \\
\hline $\begin{array}{l}\text { Alcance } \\
\text { do Teste }\end{array}$ & $\begin{array}{l}\text { Ativos de longa duração } \\
\text { mantidos para venda e para o } \\
\text { uso, incluindo propriedades } \\
\text { provadas de petróleo e gás que } \\
\text { adotam o método dos esforços } \\
\text { bem-sucedidos. Não se aplica } \\
\text { ao goodwill, ativos intangíveis, } \\
\text { ativos financeiros, impostos } \\
\text { diferidos e propriedades não } \\
\text { provadas de petróleo e gás que } \\
\text { são contabilizadas pelo método } \\
\text { dos esforços bem-sucedidos. }\end{array}$ & $\begin{array}{l}\text { Quase todos os tipos de ativos, } \\
\text { incluindo ativos fixos, ativos } \\
\text { intangíveis e goodwill. }\end{array}$ & $\begin{array}{l}\text { Aplica-se a todos os ativos } \\
\text { relevantes relacionados } \\
\text { às atividades industriais, } \\
\text { comerciais, agropecuárias, } \\
\text { minerais, financeiras, de } \\
\text { serviços e outras. Estende- } \\
\text { se aos ativos dos balanços } \\
\text { utilizados para equivalência } \\
\text { patrimonial e consolidação } \\
\text { total ou proporcional. } \\
\text { Abrange também a ativos que } \\
\text { são registrados pelo valor } \\
\text { reavaliado. }\end{array}$ \\
\hline Divulgação & $\begin{array}{l}\text { - Descrição do ativo (ou grupo } \\
\text { de ativos) que sofreu perda por } \\
\text { impairment, assim como os } \\
\text { fatos e as circunstâncias que } \\
\text { justificam o prejuízo. } \\
\text { • O valor da perda e a conta na } \\
\text { demonstração de resultado que } \\
\text { foi incluída. } \\
\text { - O método utilizado para } \\
\text { determinar valor justo. } \\
\text { - Caso o ativo (ou grupo) que } \\
\text { sofreu a perda é componente } \\
\text { de um segmento operacional, } \\
\text { respeitar as orientações } \\
\text { constantes na SFAS n. } \\
\text { Disclosures about } 131 \text { - } \text { segments }^{-} \\
\text {of an enterprise and related }_{\text {information. }}\end{array}$ & $\begin{array}{l}\text { - O valor das perdas e das } \\
\text { reversões reconhecidas no } \\
\text { resultado do período e a linha na } \\
\text { demonstração em que elas foram } \\
\text { incluídas. } \\
\text { - Os acontecimentos e } \\
\text { circunstâncias que levaram ao } \\
\text { reconhecimento ou reversão da } \\
\text { perda. } \\
\text { - Uma descrição da unidade } \\
\text { geradora de caixa (se for o caso). } \\
\text { - A metodologia de avaliação } \\
\text { para se determinar o valor } \\
\text { recuperável. } \\
\text { - Se o ativo (ou grupo de } \\
\text { ativos) que sofreu a perda for } \\
\text { componente de um segmento } \\
\text { operacional, devem ser } \\
\text { respeitadas as orientações da } \\
\text { IFRS 8: Operating Segments. }\end{array}$ & $\begin{array}{l}\text { - O valor das perdas e das } \\
\text { reversões reconhecidas no } \\
\text { resultado do período e a linha } \\
\text { na demonstração em que elas } \\
\text { foram incluídas; } \\
\text { - Os acontecimentos e } \\
\text { circunstâncias que levaram ao } \\
\text { reconhecimento ou reversão da } \\
\text { perda. } \\
\text { - Uma descrição da unidade } \\
\text { geradora de caixa (se for o } \\
\text { caso). } \\
\text { - A metodologia de avaliação } \\
\text { utilizada para se determinar o } \\
\text { valor recuperável do ativo ou } \\
\text { de uma UGC. }\end{array}$ \\
\hline
\end{tabular}




\begin{tabular}{|c|c|c|c|}
\hline $\begin{array}{l}\text { Valor } \\
\text { Recuperável }\end{array}$ & $\begin{array}{l}\text { Soma dos fluxos de caixa } \\
\text { não descontados esperados, } \\
\text { decorrentes do uso e eventual } \\
\text { venda do ativo. }\end{array}$ & $\begin{array}{l}\text { Maior valor entre o valor líquido } \\
\text { de venda de um ativo ou seu } \\
\text { valor em uso. }\end{array}$ & Idem IAS 36. \\
\hline $\begin{array}{l}\text { Apuração } \\
\text { da Perda }\end{array}$ & $\begin{array}{l}\text { Comparação do Valor Contábil } \\
\text { com o fluxo de caixa não } \\
\text { descontado gerado pelo uso } \\
\text { ou pela eventual venda do } \\
\text { ativo. Ocorrerá uma perda por } \\
\text { impairment quando o valor } \\
\text { contábil for superior ao desses } \\
\text { fluxos de caixa não descontado. }\end{array}$ & $\begin{array}{l}\text { Comparação do Valor Contábil } \\
\text { com o Valor de Recuperação } \\
\text { (maior valor entre o valor em } \\
\text { uso ou o valor de venda líquido). } \\
\text { Ocorrerá uma perda quando o } \\
\text { valor contábil for superior ao } \\
\text { valor recuperável. }\end{array}$ & Idem IAS 36. \\
\hline $\begin{array}{l}\text { Valor } \\
\text { da Perda }\end{array}$ & $\begin{array}{l}\text { Diferença entre o valor contábil } \\
\text { e o fluxo de caixa descontado } \\
\text { decorrente do uso ou da } \\
\text { eventual venda do ativo. }\end{array}$ & $\begin{array}{l}\text { Diferença entre o Valor Contábil } \\
\text { com e o Valor de Recuperação } \\
\text { (maior valor entre o valor em uso } \\
\text { ou o valor de venda líquido). }\end{array}$ & Idem IAS 36. \\
\hline $\begin{array}{l}\text { Tratamento } \\
\text { contábil }\end{array}$ & $\begin{array}{l}\text { Reduz diretamente o } \\
\text { valor contábil do ativo em } \\
\text { contrapartida a uma perda } \\
\text { operacional na apuração do } \\
\text { resultado do exercício. }\end{array}$ & $\begin{array}{l}\text { Constituição de uma provisão } \\
\text { para perda por impairment, } \\
\text { em contrapartida à reserva } \\
\text { de reavaliação (se o ativo for } \\
\text { reavaliado) e, uma despesa, } \\
\text { na apuração do resultado do } \\
\text { exercício (caso o ativo não seja } \\
\text { reavaliado ou o saldo da reserva } \\
\text { de reavaliação for insuficiente). }\end{array}$ & Idem IAS 36. \\
\hline $\begin{array}{l}\text { Reversão } \\
\text { da Perda }\end{array}$ & $\begin{array}{l}\text { Proibida a reversão da perda } \\
\text { anteriormente reconhecida. }\end{array}$ & $\begin{array}{l}\text { A reversão pode ser realizada até } \\
\text { o limite do valor contábil que } \\
\text { o ativo teria, caso a perda não } \\
\text { fosse reconhecida anteriormente. }\end{array}$ & Idem IAS 36. \\
\hline
\end{tabular}

\section{Quadro 1: Diferenças entre a Normatização Contábil para o Teste Impairment}

Fonte: Elaborado pelos autores

\section{METODOLOGIA}

Para se evidenciar e analisar as principais diferenças entre as normas internacionais de contabilidade e as normas norte-americanas, foram extraídos os aspectos relevantes de cada um dos respectivos pronunciamentos.

Para a análise de como as principais variáveis selecionadas relacionam-se com a despesa de impairment, foram consultados os relatórios anuais 10-K, 20-F e 40-F de 19 empresas integradas do setor de óleo e gás listadas na Bolsa de Valores de Nova Iorque (NYSE), levando-se em consideração o teste de impairment de reservas provadas em empresas que adotam o método de capitalização pelos Esforços Bem Sucedidos (SE) - empresas que estão no escopo da IAS 36 e da SFAS 144.

A delimitação do impairment em propriedades provadas é justificada por serem estas os principais ativos de uma empresa exploradora e produtora de petróleo. Já a escolha de empresas que seguem o método de capitalização pelos Esforços Bem-Sucedidos foi feita levando em consideração que representam a maioria e também as maiores do setor.

As empresas consultadas foram: Chevron, ConocoPhillips, Exxon Mobil, Hess, Marathon e Murphy (EUA), Petro-Canada e Suncor (Canadá); BP (Reino Unido); China Petroleum e PetroChina (China); ENI (Itália); Royal Dutch Shell (Holanda); StatoilHydro (Noruega); Total (França); Repsol (Espanha); Sasol (África do Sul); YPF (Argentina); Petrobras (Brasil).

Inicialmente, o período de tempo determinado para a coleta dos dados se refere aos relatórios dos 
exercícios sociais de 2002 a 2008. Esse intervalo de tempo foi definido com base na vigência da norma SFAS 144, emitida em agosto de 2001 e exigida para os exercícios sociais iniciados em 2002. No entanto, nem todas as empresas tinham seus relatórios arquivados na NYSE para o ano de $2002 \mathrm{e}$, consequentemente, não estavam sob as exigências da SEC. Assim, para uma maior padronização da amostra, foi determinado o levantamento dos relatórios a partir do ano de 2003, obtendo-se 19 empresas, 6 anos de análise para cada uma e 114 observações.

Definida a amostra, foram levantados os valores das seguintes variáveis para cada empresa em cada um dos anos: despesa de impairment total; despesas de impairment atribuída aos ativos de E\&P (DIE\&P); volume de reservas provadas (RP); volume de produção (PROD); volume de descobertas (DESC); volume de revisões (REV); volume de melhorias de recuperação (MELH); volume de compras (COMP); volume de vendas (VEND); e preço de venda do petróleo (PREÇO_PETRO).

Os valores das variáveis relacionadas ao preço de venda do petróleo e despesa de impairment foram levantados em dólares.

Os valores das variáveis relacionadas a volumes de óleo foram levantados em barris (petróleo); e em pés cúbicos para os volumes de gás. Posteriormente, os volumes de gás foram transformados em "barril de óleo equivalente" (boe). Cada barril de óleo corresponde a aproximadamente 6.000 pés cúbicos de gás (equivalência de conteúdo energético - British Thermal Unit). Após essa transformação, as variáveis de gás foram somadas às variáveis equivalentes de óleo.

Posteriormente, as variáveis "descobertas", "revisões" e "melhorias na recuperação" foram somadas constituindo uma única variável (DESC). Na essência, esaas três variáveis representam aumento de reservas obtido por ganho de eficiência - novas reservas. Este procedimento está de acordo com as orientações do SFAS 69. O referido pronunciamento faculta a divulgação dessas variáveis somadas às Descobertas quando os valores não forem significativos. Na essência, essas variáveis representam alterações nos volumes de reservas, seja por novas descobertas ("descobertas"), pela obtenção de novas informações que alteraram as estimativas anteriores de avaliação das reservas ("revisões") ou pelo aperfeiçoamento operacional do processo de recuperação de reservas ("melhorias na recuperação"). Todas elas se originam do acesso a novas informações antes não dominadas pela empresa (GALLUN, STEVENSON e NICHOLS, 1993).

Por fim, foi calculada a diferença entre as variáveis "compras de óleo e gás" e "venda de óleo e gás", com o objetivo de se obter um valor líquido (COMP_VEND). Isso se justifica pelo motivo de que essas operações (compra e venda de reservas) não são recorrentes, pois não constituem objetivo das empresas analisadas - exploração e produção.

De posse dessas informações, os dados foram testados quanto à normalidade, com o teste de Kolmogorov-Smirnov, e posteriormente os valores que apresentaram distribuição normal foram submetidos ao teste paramétrico de correlação de Pearson (que pressupõe uma população normal bivariada), enquanto os não normais foram submetidos ao teste não paramétrico de correlação de Spearman.

A análise foi feita calculando-se coeficientes de correlação para as 19 empresas selecionadas, cada uma em um período de tempo de 6 anos. Os resultados foram, então, avaliados em conjunto, não se atendo aos resultados individuais de cada empresa.

Destaca-se ainda que o objetivo do cálculo do coeficiente de correlação não está ligado à formulação de modelos de regressão que objetivam predizer o valor da despesa de impairment. Pretendem-se identificar indícios do comportamento das variáveis levantadas para que, a partir deles, possam ser realizadas inferências acerca dos fatores que influenciam o valor da despesa de impairment atribuída ao segmento de E\&P.

\section{PROPOSIÇÕES DA PESQUISA}

Diante do problema exposto e da revisão conceitual e normativa apresentada, levantam-se duas proposições básicas e mais três complementares à segunda proposição básica: 
Proposição 1: O Preço do petróleo e despesa de impairment devem apresentar comportamentos inversos.

Proposição 2: $O$ volume de reservas e a despesa de impairment devem apresentar comportamentos inversos.

Proposição 2.1: O volume produzido e a despesa de impairment devem apresentar comportamentos iguais.

Proposição 2.2: O volume de descobertas e a despesa de impairment devem apresentar comportamentos inversos.

Proposição 2.3: $O$ resultado da diferença entre o volume comprado e o volume vendido de óleo e gás e a despesa de impairment devem apresentar comportamentos inversos.

\section{EVIDÊNCIAS EMPÍRICAS DE IMPAIRMENT NO SETOR PETROLÍFERO}

Das 19 empresas selecionadas para amostra, com 6 anos para cada empresa, foram consultados 114 relatórios financeiros. Desse total, 12 (11\%) foram do tipo 40-F; 66 (58\%) foram do tipo 20-F; e $36(32 \%)$ foram do tipo $10-\mathrm{K}$.

Com relação à consolidação das demonstrações financeiras, 76 (67\%) relatórios estavam consolidados em US GAAP e 38 (32\%) em IFRS. Depreende-se, portanto, que a maioria das empresas da amostra é de títulos privados estrangeiros e preferem as normas norte-americanas para a consolidação de suas demonstrações financeiras.

As médias, considerando as 114 empresas-ano, foram de 270.924.441 dólares de impairment total e 119.828.085 dólares de impairment atribuído ao segmento de E\&P.

O maior valor de impairment divulgado foi de 2.455 milhões de dólares, da PetroChina no ano de 2008, justificados como sendo constituídos de 620 milhões em ativos de E\&P e 1.835 milhões em equipamentos e maquinários em geral. Nesse mesmo ano, foi divulgada uma revisão negativa de 467.833.333 boe no volume total de reservas provadas da empresa. Ressalta-se ainda a tendência de crescimento observada na quantidade produzida pela empresa de óleo e gás.

O menor valor foi divulgado pela $Y P F$ na cifra de 658.762 dólares no ano de 2005. Esse valor foi totalmente atribuído ao segmento de E\&P e foi também o menor valor divulgado para o segmento. Nesse ano, a empresa atingiu 2.351.749.489 boe de reservas provadas, o seu maior volume nos anos estudados.

O maior valor de impairment atribuído ao segmento de E\&P foi feito pela BP no ano de 2008 (ver efeito no Gráfico 1), no valor de 1.186 milhões de dólares. Esse valor é atribuído pela empresa, principalmente, à perda de recuperação a) em propriedades de óleo e gás no Golfo do México, no valor de \$270 milhões, provocada por revisões decrescentes das reservas; b) em ativos de E\&P no Vietnã, no valor de \$210 milhões, resultado de uma decisão da BP de retirar-se das atividades exploratórias na referida área; c) em propriedades de óleo e gás no Egito, no valor de \$85 milhões provocada por aumentos dos custos; e d) em outros ativos individualmente insignificantes que causaram a perda de \$104 milhões (como divulgado pela empresa). Registra-se ainda a revisão negativa feita pela empresa no ano de 2008 no volume de 593 bilhões de pés cúbicos em suas reservas de gás.

A Tabela 1 apresenta os valores médios das despesas de impairment durante os 6 anos estudados. As siglas DI_TOTAL e DI_EP significam, respectivamente, Despesa de Impairment Total divulgada pela empresa e Despesa de Impairment atribuída aos ativos de E\&P. A variável DI_EP/DI_TOTAL representa, portanto, a porcentagem de participação da despesa de impairment atribuída aos ativos de E\&P na despesa de impairment total da empresa. 
Tabela 1: Médias de Impairment (em US\$)

\begin{tabular}{|c|c|c|c|}
\hline NOME & DI_TOTAL & DI_EP & DI_EP/DI_TOTAL \\
\hline $\mathrm{BP}$ & 1.085 .833 .333 & 566.333 .333 & $52 \%$ \\
\hline Chevron & 340.000 .000 & 133.000 .000 & $39 \%$ \\
\hline China Petroleum & 430.730 .006 & 178.543 .090 & $41 \%$ \\
\hline ConocoPhillips & 566.166 .667 & 299.166 .667 & $53 \%$ \\
\hline ENI & 304.312 .212 & 177.316 .444 & $58 \%$ \\
\hline Exxon Mobil & - & - & - \\
\hline Hess & 91.000 .000 & 36.500 .000 & $40 \%$ \\
\hline Marathon & 502.000 .000 & 24.000 .000 & $5 \%$ \\
\hline Murphy & 14.990 .750 & 2.800 .000 & $19 \%$ \\
\hline Petro-Canada & 59.055 .114 & 59.055 .114 & $100 \%$ \\
\hline Petrobras & 183.666 .667 & 138.833 .333 & $76 \%$ \\
\hline PetroChina & 640.799 .873 & 299.510 .277 & $47 \%$ \\
\hline Repsol & 118.302 .696 & 76.341 .597 & $65 \%$ \\
\hline Royal Dutch Shell & 808.333 .333 & 265.833 .333 & $33 \%$ \\
\hline Sasol & 61.610 .899 & 13.108 .335 & $21 \%$ \\
\hline StatoilHydro & 335.899 .689 & 283.572 .928 & $84 \%$ \\
\hline Suncor & 7.995 .335 & 7.995 .335 & $100 \%$ \\
\hline TOTAL. & 173.535 .605 & 90.357 .139 & $52 \%$ \\
\hline YPF & 26.204 .197 & 26.204 .197 & $100 \%$ \\
\hline
\end{tabular}

Fonte: Elaborado pelos autores

Apesar de a PetroChina ter sido responsável pelo maior valor absoluto de impairment total de uma empresa, na média dos anos estudados, essa marca ficou com a $B P$, que também registrou a maior média atribuída ao segmento de E\&P. Esse fato justifica-se devido a PetroChina ter registrado um valor esporádico de impairment no ano de 2008, tendo nos anos anteriores uma média relativamente pequena de 277.797 mil dólares de impairment.

O menor valor médio de impairment foi registrado pela Suncor, que não corresponde à empresa que registrou o menor valor absoluto, que foi a $Y P F$. Especificamente para o segmento de E\&P, o menor valor médio é atribuído à Murphy. Em valores absolutos esta marca também ficou com a YPF.

Com relação à participação da despesa de impairment de E\&P na despesa de impairment total da empresa, destaca-se a baixa porcentagem média da Marathon e as altas porcentagens registradas pelas Petro-Canada, Suncor e YPF, que atribuíram, em média, 100\% de suas despesas de impairment ao segmento de E\&P.

Destaca-se também o fato de a Exxon Mobil não ter registrado, para o período estudado, nenhum valor de despesa de impairment.

As despesas de impairment foram, ainda, analisadas em seus valores médios ano a ano, considerando as 19 empresas. O Gráfico 1 apresenta a média de despesa de impairment total das empresas e atribuídas ao segmento de E\&P. 


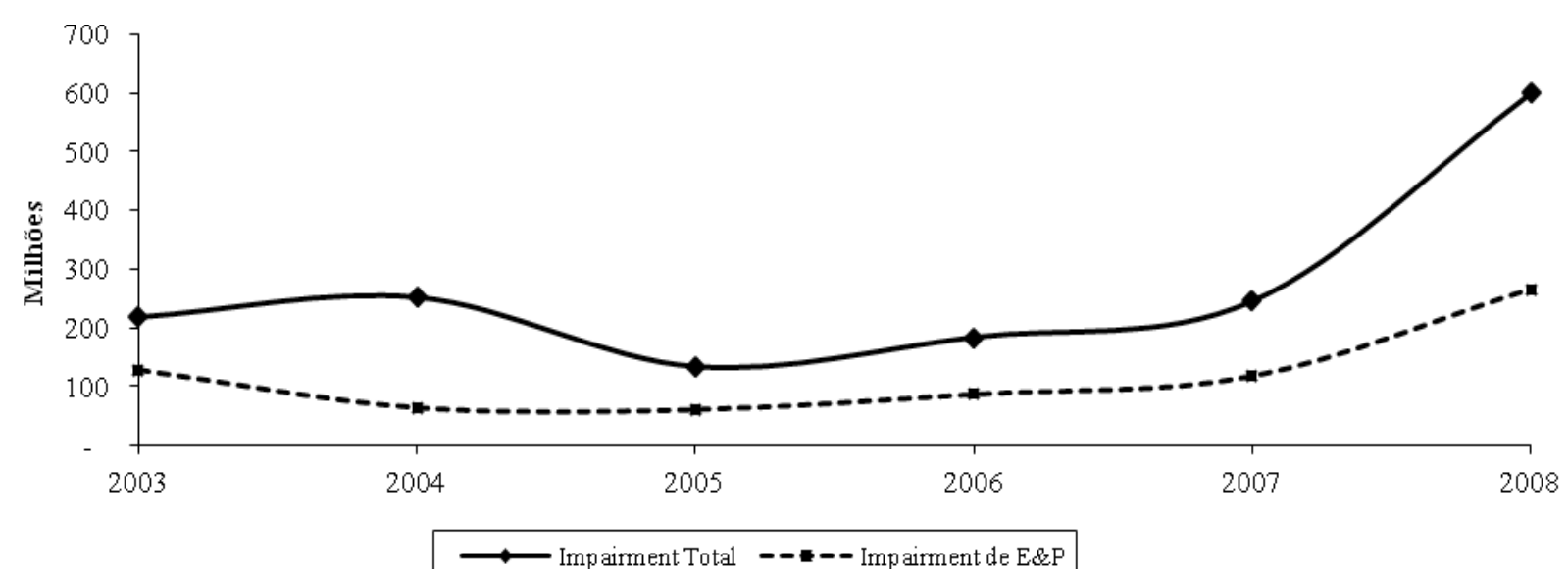

Gráfico 1: Média Anual de Despesas de Impairment

Fonte: Elaborado pelos autores

A análise das relações entre as variáveis selecionadas e a despesa de impairment foi feita levando-se em consideração cada uma das 19 empresas, com 6 anos cada uma $(\mathrm{n}=6)$; e cada uma das variáveis para as 114 empresas-ano. Não foi considerada significância estatística, visto que foi dada ênfase no sinal do coeficiente de correlação para se identificar o comportamento entre as variáveis.

As Tabelas 2 e 3 resumem os dados apresentados. Na Tabela 2, são apresentados os coeficientes de correlação entre as despesas de impairment e as variáveis analisadas - respectivamente, preço do petróleo, reservas provadas, descobertas, produção e saldo entre compras e vendas de reservas. Os coeficientes da Tabela 2 que se apresentam sombreados representam aqueles que se comportaram de acordo com as proposições apresentadas.

Tabela 2: Coeficientes de Correlação

\begin{tabular}{l|c|c|c|c|c}
\hline \multicolumn{1}{c|}{ NOME } & DI X PREÇO_PETRO & DI X RP & DI X DESC & DI X PROD & DI X COMP_VEND \\
\hline BP & 0,22 & 0,70 & 0,50 & 0,57 & 0,66 \\
\hline Chevron & $-0,45$ & 0,63 & 0,49 & $-0,40$ & 0,45 \\
\hline China Petroleum & 0,64 & 0,52 & $-0,25$ & $-0,68$ & - \\
\hline ConocoPhillips & 0,79 & 0,27 & $-0,41$ & $-0,59$ & $-0,69$ \\
\hline ENI & 0,45 & 0,33 & $-0,50$ & $-0,18$ & $-0,45$ \\
\hline Exxon Mobil & - & - & - & - & - \\
\hline Hess & 0,31 & 0,62 & 0,63 & $-0,52$ & $-0,58$ \\
\hline Marathon & 0,68 & $-0,43$ & $-0,25$ & $-0,45$ & 0,30 \\
\hline Murphy & $-0,22$ & 0,70 & $-0,23$ & 0,21 & $-0,44$ \\
\hline Petro-Canada & 0,60 & $-0,25$ & $-0,35$ & $-0,25$ & 0,42 \\
\hline Petrobras & 0,71 & $-0,44$ & $-0,33$ & 0,65 & $-0,37$ \\
\hline PetroChina & 0,62 & 0,43 & $-0,21$ & $-0,58$ & - \\
\hline Repsol & 0,00 & $-0,29$ & $-0,70$ & $-0,40$ & $-0,54$ \\
\hline Royal Dutch Shell & $-0,33$ & 0,23 & $-0,19$ & $-0,37$ & $-0,65$ \\
\hline Sasol & 0,72 & 0,34 & $-0,37$ & $-0,62$ & - \\
\hline StatoilHydro & 0,45 & 0,68 & 0,51 & $-0,61$ & $-0,45$ \\
\hline Suncor Energy & $-0,84$ & $-0,51$ & $-0,27$ & 0,52 & $-0,34$ \\
\hline TOTAL & 0,59 & $-0,69$ & $-0,67$ & 0,20 & $-0,38$ \\
\hline YPF & 0,19 & $-0,22$ & 0,68 & 0,24 & $-0,66$ \\
\hline POF & & & & \\
\hline
\end{tabular}

Fonte: Elaborado pelos autores 
A Tabela 3 complementa a Tabela 2 e deve ser entendida da seguinte forma: células com a letra $\mathrm{S}$ representam os casos em que a relação da variável com despesas de impairment foi de acordo com a proposição formulada. Já células com a letra $\mathrm{N}$ representam os casos em que a relação da variável com despesas de impairment não foi de acordo com a proposição formulada. As margens esquerdas e inferior mostra a quantidade e a porcentagem de $\mathrm{S}$ e $\mathrm{N}$ na amostra.

Tabela 3: Aderência dos Resultados às Proposições

\begin{tabular}{|c|c|c|c|c|c|c|c|c|c|}
\hline NOME & $\begin{array}{c}\text { DI X PREÇO_ } \\
\text { PETRO }\end{array}$ & $\begin{array}{c}\text { DI X } \\
\text { RP }\end{array}$ & $\begin{array}{c}\text { DI X } \\
\text { PROD }\end{array}$ & $\begin{array}{c}\text { DI X } \\
\text { DESC }\end{array}$ & $\begin{array}{c}\text { DI X COMP_ } \\
\text { VEND }\end{array}$ & $\mathbf{S}$ & $\mathbf{N}$ & $\mathrm{S}(\%)$ & $\begin{array}{c}N \\
(\%)\end{array}$ \\
\hline BP & $\mathrm{N}$ & $\mathrm{N}$ & $\mathrm{S}$ & $\mathrm{N}$ & $\mathrm{N}$ & 1 & 4 & $20 \%$ & $80 \%$ \\
\hline Chevron & S & $\mathrm{N}$ & $\mathrm{N}$ & $\mathrm{N}$ & $\mathrm{N}$ & 1 & 4 & $20 \%$ & $80 \%$ \\
\hline $\begin{array}{l}\text { China } \\
\text { Petroleum }\end{array}$ & $\mathrm{N}$ & $\mathrm{N}$ & $\mathrm{N}$ & $\mathrm{S}$ & - & 1 & 3 & $25 \%$ & $75 \%$ \\
\hline Conoco Phillips & $\mathrm{N}$ & $\mathrm{N}$ & $\mathrm{N}$ & $\mathrm{S}$ & $\mathrm{S}$ & 2 & 3 & $40 \%$ & $60 \%$ \\
\hline ENI & $\mathrm{N}$ & $\mathrm{N}$ & $\mathrm{N}$ & $S$ & $S$ & 2 & 3 & $40 \%$ & $60 \%$ \\
\hline Exxon Mobil & - & - & - & - & - & $\mathbf{0}$ & $\mathbf{0}$ & - & - \\
\hline Hess & $\mathrm{N}$ & $\mathrm{N}$ & $\mathrm{N}$ & $\mathrm{N}$ & $\mathrm{S}$ & 1 & 4 & $20 \%$ & $80 \%$ \\
\hline Marathon & $\mathrm{N}$ & $S$ & $\mathrm{~N}$ & $S$ & $\mathrm{~N}$ & 2 & 3 & $40 \%$ & $60 \%$ \\
\hline Murphy & $\mathrm{S}$ & $\mathrm{N}$ & $\mathrm{S}$ & $\mathrm{S}$ & $\mathrm{S}$ & 4 & 1 & $80 \%$ & $20 \%$ \\
\hline Petro-Canada & $\mathrm{N}$ & $\mathrm{S}$ & $\mathrm{N}$ & $\mathrm{S}$ & $\mathrm{N}$ & 2 & 3 & $40 \%$ & $60 \%$ \\
\hline Petrobras. & $\mathrm{N}$ & $\mathrm{S}$ & $\mathrm{S}$ & $\mathrm{S}$ & $S$ & 4 & 1 & $80 \%$ & $20 \%$ \\
\hline PetroChina & $\mathrm{N}$ & $\mathrm{N}$ & $\mathrm{N}$ & $\mathrm{S}$ & $-\mathrm{s}$ & 1 & 3 & $25 \%$ & $75 \%$ \\
\hline Repsol & $\mathrm{S}$ & S & $\mathrm{N}$ & $\mathrm{S}$ & $\mathrm{S}$ & 4 & 1 & $80 \%$ & $20 \%$ \\
\hline $\begin{array}{l}\text { Royal Dutch } \\
\text { Shell }\end{array}$ & S & $\mathrm{N}$ & $\mathrm{N}$ & S & $\mathrm{S}$ & 3 & 2 & $60 \%$ & $40 \%$ \\
\hline Sasol Limited & $\mathrm{N}$ & $\mathrm{N}$ & $\mathrm{N}$ & $\mathrm{S}$ & - & 1 & 3 & $25 \%$ & $75 \%$ \\
\hline StatoilHydro & $\mathrm{N}$ & $\mathrm{N}$ & $\mathrm{N}$ & $\mathrm{N}$ & $\mathrm{S}$ & 1 & 4 & $20 \%$ & $80 \%$ \\
\hline Suncor. & $\mathrm{S}$ & $\mathrm{S}$ & $\mathrm{S}$ & $\mathrm{S}$ & $\mathrm{S}$ & 5 & $\mathbf{0}$ & $100 \%$ & $0 \%$ \\
\hline TOTAL. & $\mathrm{N}$ & $\mathrm{S}$ & $\mathrm{S}$ & $\mathrm{S}$ & $\mathrm{S}$ & 4 & 1 & $80 \%$ & $20 \%$ \\
\hline YPF & $\mathrm{N}$ & $\mathrm{S}$ & $\mathrm{S}$ & $\mathrm{N}$ & $\mathrm{S}$ & 3 & 2 & $60 \%$ & $40 \%$ \\
\hline $\mathrm{S}$ & 5 & 7 & 6 & 13 & 11 & & & & \\
\hline $\mathrm{N}$ & 13 & 11 & 12 & 5 & 4 & & & & \\
\hline S (\%) & $28 \%$ & $39 \%$ & $33 \%$ & $72 \%$ & $73 \%$ & & & & \\
\hline $\mathrm{N}(\%)$ & $72 \%$ & $61 \%$ & $67 \%$ & $28 \%$ & $27 \%$ & & & & \\
\hline
\end{tabular}

Fonte: Elaborado pelos autores

Para melhor entendimento, os resultados são apresentados para cada proposição levantada.

- $\quad$ Proposição 1: Das 18 empresas nas quais foram reconhecidas perdas por impairment (a Exxon Mobil não reconheceu), em apenas 5 empresas, 28\%, a relação entre as variáveis preço do petróleo e despesas de impairment foi condizente com a proposição 1. Foram elas Chevron, Murphy, Repsol, Royal Dutch Shell e Suncor.

- $\quad$ Proposição 2: Em 39\% das empresas, a relação entre reservas provadas e despesas de impairment teve comportamento de acordo com a proposição 2 - Marathon, Petro-Canada, Petrobras, Repsol, Suncor, TOTAL e YPF. 
- $\quad$ Proposição 2.1: Em 8 das 18 empresas que apresentaram despesas de impairment, o volume produzido relacionou-se de forma positiva (semelhante) à despesa de impairment, ou seja, em 33\% das ocorrências - BP., Murphy, Petrobras, Suncor, TOTAL e YPF.

- Proposição 2.2: O comportamento da variável descoberta se portou de acordo com a proposição 2.2 em 13 das 18 empresas. Assim, pode-se inferir que em 72\% das empresas da amostra o volume de descobertas relacionou-se de forma inversa com despesas de impairment. As empresas são: China Petroleum, ConocoPhillips, ENI, Marathon, Murphy, Petro-Canada, Petrobras, PetroChina, Repsol, Royal Dutch Shell, Sasol, Suncor e TOTAL.

- $\quad$ Proposição 2.3: A diferença líquida entre a quantidade comprada e vendida de reservas de óleo e gás apresentou comportamento de acordo com a proposição levantada em 11 das 15 ocorrências, $73 \%$, ou seja, na medida em que a diferença (compra - venda) aumentou, a despesa de impairment diminuiu - ConocoPhillips, ENI, Hess, Murphy, Petrobras, Repsol, Royal Dutch Shell, StatoilHydro, Suncor, TOTAL e YPF.

Com base nos resultados apresentados, observa-se que as variáveis que mais se comportaram de acordo com as proposições foram descobertas (DESC), 72\%, e quantidade comprada líquida de óleo e gás (COMP_VEND), 73\%.

A variável COMP_VEND, que apresentou alta relação com as despesas de impairment, foi evidenciada por apenas 15 empresas em seus relatórios e apresenta baixa influência relativa na variação das reservas provadas das empresas estudadas.

A descoberta de reservas de petróleo ocorre como consequência da exploração; a produção dessas reservas usualmente inicia-se depois da descoberta e termina muitos anos depois quando o poço ou campo é abandonado. Assim, para as empresas que exploram e produzem petróleo, a descoberta de uma nova jazida é o fator econômico mais importante da atividade. Na verdade, representa o principal evento econômico desse setor, evidentemente, até mais do que os lucros e as receitas contábeis derivadas das vendas do óleo e do gás, pois é com a sua efetivação - confirmação da existência descoberta de reservas economicamente viáveis - que se inicia todo o processo produtivo. Dos resultados obtidos, depreende-se que o volume de descobertas influencia e interfere no reconhecimento da despesa de impairment atribuída ao segmento de E\&P.

A ideia é que as reservas petrolíferas são os ativos que viabilizam a existência da empresa que explora e produz petróleo e gás. Assim os valores dessas variáveis servem como parâmetros para, entre outras coisas, avaliar a capacidade da empresa de localizar reservas de petróleo economicamente viáveis.

Em essência, as variáveis identificadas influenciam e devem ser premissas levadas em consideração no cálculo do valor de recuperação de um ativo de E\&P. Portanto, empresas que mantém uma taxa constante de descobertas tendem a reconhecer menos impairment para o segmento, pois o aumento dessa variável significa recuperabilidade maior dos ativos de E\&P.

\section{CONSIDERAÇÕES FINAIS}

Este estudo objetivou identificar como as variáveis, consideradas como sendo situações adversas causadoras de impairment, relacionam-se com a perda do valor de recuperação dos ativos de E\&P. De forma geral, identifica o impacto do preço do petróleo e das alterações no volume de reservas provadas sobre a perda do valor de recuperação (impairment) atribuída aos ativos de E\&P de empresas do setor petrolífero.

Observou-se, principalmente, a relação inversa da despesa de impairment atribuída ao segmento de E\&P com os valores de descobertas. Portanto, empresas que apresentam uma taxa constante de descobertas tendem a reconhecer menos impairment para o segmento, pois o aumento das reservas provadas significa maior recuperabilidade dos ativos de E\&P. 


\section{repec}

Na prática do teste de recuperabilidade dos valores registrados dos ativos, está implícita uma das principais características da indústria petrolífera - o risco existente em encontrar, ou não, reservas minerais economicamente viáveis.

Dessas informações, depreende-se que os ativos da indústria de petróleo e gás, especialmente no segmento de E\&P, apresentam características específicas não somente em decorrência dos métodos de capitalização dos gastos, mas também em relação à identificação dos benefícios futuros gerados por esses ativos.

Como possíveis limitações do presente trabalho, é importante mencionar dois fatos: 1) o pequeno espaço de tempo, seis anos, considerado para cada empresa analisada (2003 a 2008), o que fez com que não se levasse em consideração a significância estatística no cálculo do coeficiente de correlação; e 2) o espaço de tempo selecionado (janela temporal) ser caracterizado pelo constante aumento do preço do petróleo, o que pode ter influenciado na conclusão de que a variável "preço" não se comportou de acordo com a proposição.

Por fim, no decorrer dessa pesquisa, diversas questões foram levantadas, o que garante ao tema impairment um campo vasto para pesquisas e novos estudos. No universo de possibilidades, recomenda-se um estudo que objetive identificar como a qualidade das descobertas influencia na capacidade de ampliação do fluxo de caixa dos ativos de E\&P e, consequentemente, na diminuição das perdas de recuperabilidade (impairment).

\section{REFERÊNCIAS}

AMPOFO, A. A.; SELLANI, R. J. Examining the differences between United States Generally Accepted Accounting Principles (U.S. GAAP) and International Accounting Standards (IAS): implications for the harmonization of accounting standards. Accounting Fórum. v. 29, p. 219-231, 2005.

ALCIATORE, M. L.; EASTON, P.; SPEAR, N. Accounting for the impairment of long-lived assets: evidence from the petroleum industry. Journal of Accounting and Economics, v. 29, p. 151-172, 2000.

BROCK, H. R; CARNES, M. Z.; JUSTICE, R, Petroleum accounting: principles, procedures \& issues. $6^{\circ}$ Ed. Denton, Texas: PricewaterhouseCoopers/Professional Development Institute, 2007.

CLÔ, A. Oil Economics and Policy. Boston: Kluwer Academic Publishers, 2000.

CPC - Comitê de Pronunciamentos Contábeis. Pronunciamento Técnico CPC 01 - Redução ao Valor Recuperável de Ativos. Setembro, 2007.

CPC - Comitê de Pronunciamentos Contábeis. A Busca da Convergência da Contabilidade aos Padrões Internacionais. Brasília. Maio de 2007. 33 p. Disponível em $<$ http://www.cpc.org.br/pdf/Livreto_CPC_atualizado_230507.pdf> Acesso em jan.2009.

ERNEST \& YOUNG e FIPECAFI. Manual de Normas Internacionais de Contabilidade: IFRS versus Normas Brasileiras. Editora Atlas. São Paulo: 2009.

FASB - Financial Accounting Standards Board. Statements of Financial Accounting Standards $\mathbf{n}^{\circ} 144$ - Accounting for the Impairment or Disposal of Long-Lived Assets. Agosto, 2001.

GALLUN, R.A.; STEVENSON, J.W.; NICHOLS, L.M. Fundamentals of Oil \& Gas Accounting. $3^{\text {a }}$ Ed. Oklahoma: PennWell Books, 1993. 
GODOY, C. R. Evidenciação contábil e as avaliações pelo fluxo de caixa descontado e pela teoria de opções: um estudo aplicado à indústria petrolífera mundial. 2004. $284 \mathrm{f}$. Tese (Doutorado em Controladoria e Contabilidade) - Universidade de São Paulo, Faculdade de Economia, Administração e Contabilidade. São Paulo, 2004.

IASB - International Accounting Standards Board. International Accounting Standards n⿳0 36 - Impairment of Assets. Junho, 1998.

IASB - International Accounting Standards Board. International Financial Reporting Standards $\mathbf{n}^{\circ}$ 6 - Exploration for and Evaluation of Mineral Resources. Dezembro, 2004.

IJIRI, Y. Oil and Gas Accounting - Turbulence in Financial Reporting. Financial Executive. August, 1979.

MARTINS, E.; SANTOS, A. A Nova Lei das S/A e a Internacionalização da Contabilidade: Ativo Imobilizado - Teste de Recuperabilidade. Julho, 2008. Disponível em: <http://www.cfc.fipecafi.org/>. Acesso em jan.2009.

MARTINS, E. Entrevista: País está mais bem preparado para a mudança. Valor Online. São Paulo: 2008. Disponível em: <http:// www.fenacon.org.br/pressclipping/2008/fevereiro/ve/ve260208b.htm>. Acesso em jan. 2009.

REINSTEIN, A.; LANDER, G. H. Implementing the impairment of assets requirements of SFAS nº 144. An empirical analysis. Managerial Auditing Journal. v. 19, n. 3, p. 400-411, 2004.

RIELD, E. J. An examination of long-lived asset impairments. The Accounting Review. n. 3, v. 79. p. 823-852. 2004.

STICKNEY, C. P.; WEIL, R. L. Contabilidade financeira: uma introdução aos conceitos, métodos e usos. São Paulo: Editora Atlas, 2001.

WOLK, H. I., FRANCIS, J.R. and TEARNEY, M.G. Accounting Theory: A Conceptual and institutiobal Approach. Massachusetts: Kent Publishing Company, 1984. 